\title{
Zur Bestimmung des Eisens in Puddelschlacken.
} Von

\section{Blum.}

Die Puddelschlacken sind heute ein sehr gangbares Untersuchungsobject in Eisenhüttenlaboratorien, und die zwischen Käufer und Verkäufer ausgewechselten Analysen weisen oft grosse Differenzen im Eisengehalte auf.

Ich möchte nun mit diesen Zeilen auf eine Fehlerquelle aufmerksam machen, welche den beiden am bäufigsten angewandten Titrationsmethoden der Eisenbestimmung - nämlich der Permanganat-, sowie der Zinnchlorürmethode - anhaftet, wenn dieselben zur Bestimmung des Eisens in Puddelschlacken angewandt werden, und welche auf einem fast nie fehlenden Vanadinsäuregehalte derselben beruht. Wegen der leichten Oxydirbarkeit des metallischen Vanadiums findet sich fast der sanze Vanadiumgehalt des Roheisens in den Puddelschlacken angereichert wieder, so dass selbst beim Verpuddeln schwach vanadiumhaltigen Eisens der Vanadinsäuregehalt der Schlacke je nach dem Abbrand nicht selten 0,5 bis $1,0 \%$ beträgt. Wird nun bei der Analyse dieser Schlacke dieselbe nach vorherigem Schmelzen mit Natrium-Kaliumearbonat oder auch durch directes Behandeln mit Königswasser oder Bromsalzsäure in Lösung gebracht, so finden wir den Fanadiumgehalt derselben in der Auflösung als Vanadinsäure vorhanden. Soll das Eisen in dieser Lösung nach der Marguerite'schen Permanganatmethode bestimmt werden, so muss dieselbe, nachdem sie durch Abdampfen mit Schwefelsüure in eine schwefelsaure übergeführt worden ist, durch metallisches Zink reducirt werden. Hierdurch wird neben dern Ferrisalz auch die Vanadinsäure reducirt und bildet die entsprechenden Vanadoxydsalze $(\mathrm{Czudnowicz})^{1}$, welche beim nachherigen Titriren mit Kaliumpermanganatlösung wieder in Vanadinsäure übergeführt werden. Es findet also ein Mehrverbrauch an Permanganatlösung statt, wodurch der Eisengehalt der Schlacke zu hoch gefunden wird. Bekanntlich haben Manasse ${ }^{2}$ ) und L'Hôte ${ }^{3}$ ) auf diese, in saurer Lösung stattfindende Oxydation des Vanadoxydes zu Vanadinsäure durch Kalium-

1) Diese Zeitschrift 3, 379 .

2) Diese Zeitschrift 32, 223.

3) Diese Zeitschrift 32, 232. 
permanganat eine maassanalytische Methode zur Bestimmung dieser begründet.

Da Zinnchlorür ebenfalls Vanadinsäure reducirt, so tritt bei Anwendung der Zinnchlorürmethode zur Bestimmung des Eisens derselbe Fehler ein, nämlich der Eisengehalt wird auch in diesem Falle zu hoch gefunden.

Aus diesen Ursachen müssen die beiden vorerwähnten Methoden zur Bestimmung des Eisens in Puddelschlacken ausgeschlossen werden, falls man nicht die Gewissheit von der vollständigen Abwesenheit des Vanadiums in dem jeweiligen Untersuchungsobjecte hat. Bei der allgemeinen Verbreitung des Vanadiums im Mineralreiche dürfte dieser Fall nicht vorzusehen sein, und man kann absolut einwandsfreie Resultate nur durch die Gewichtsbestimmung erreichen, wobei man folgendermaassen zu verfahren hat:

Die von der Kieselsäure abfiltrirte chlorwasserstofisaure Lösung von etwa $0,5 \mathrm{~g}$ Substanz, in welcher das Eisen als Chlorid enthalten sein muss, wird mit Ammoniumcarbonat neutralisirt, mit Wasser verdünnt und unter Kochen mit Ammoniumacetat gefällt. Der abfiltrirte Niederschlag wird in Salzsäure gelöst, and die Fällung noch einmal wiederholt, wodurch eine vollständige Abscheidung des in Puddelschlacken nie fehlenden Mangangehaltes erreicht wird. Der mit warmem Wasser ausgewaschene Niederschlag wird wieder in Salzsäure gelöst, mit so viel Weinsteinsäurelösung versetzt, dass auf Zusatz von Ammoniak kein Niederschlag entsteht, dann fällt man mit Schwefelammonium im Ueberschuss und lässt längere Zeit in gelinder Wärme absitzen. Hierbei bleibt Schwefelvanadium neben der Phosphorsäure und etwa vorhandenen kleinen Mengen Thonerde und Kalk in Auflösung. Das abgeschiedene Schwefeleisen wird auf ein geräumiges Filter abfiltrirt und nach dem vollständigen Auswaschen mit schwefelammoniumhaltigem Wasser in verdünnter Salzsäure gelöst, mit Salpetersäure oxydirt, die Lösung vom abgeschiedenen Schwefel abfiltrirt, mit Ammoniak gefällt, gekocht, filtrirt, mit warmem Wasser ausgewaschen und getrocknet. Das Filter wird für sich am Platindraht eingeäschert, and dann der Niederschlag geglübt und als Eisenoxyd gewogen.

Die Methode ist sebr zeitraubend and unständlich, doch bleibt sie bei solchen Analysen, wo es sich um eine Bestimmung des Eisens neben Vanadium und Mangan handelt, die einzig anwendbare, welche dje genaue Trennung dieser Körper von Eisen gestattet. 